\title{
Dose-ranging pilot randomized trial of amino acid mixture combined with physical activity promotion for reducing abdominal fat in overweight adults
}

This article was published in the following Dove Press journal: Diabetes, Metabolic Syndrome and Obesity:Targets and Therapy 6 July 2017

Number of times this article has been viewed

\author{
Hiroyuki Sasai ${ }^{1-3, *}$ \\ Keisuke Ueda ${ }^{4,5, *}$ \\ Takehiko Tsujimoto 6,7 \\ Hiroyuki Kobayashi' \\ Chiaki Sanbongi ${ }^{4}$ \\ Shuji Ikegami ${ }^{4}$ \\ Yoshio Nakata' \\ 'Faculty of Medicine, University of \\ Tsukuba, Tsukuba, Ibaraki, 2Japan \\ Society for the Promotion of Science, \\ Chiyoda, Tokyo, ${ }^{3}$ Department of \\ Life Sciences, Graduate School of \\ Arts and Sciences, The University of \\ Tokyo, Meguro, Tokyo, ${ }^{4}$ Food Science \\ Research Laboratories, Meiji Co., Ltd., \\ Odawara, Kanagawa, ${ }^{5} \mathrm{Graduate}$ School \\ of Comprehensive Human Sciences, \\ ${ }^{6}$ Faculty of Health and Sport Sciences, \\ University of Tsukuba, Tsukuba, \\ Ibaraki, ${ }^{7}$ Faculty of Human Sciences, \\ Shimane University, Matsue, Shimane, \\ Japan
}

*These authors contributed equally to this work
Correspondence: Yoshio Nakata Faculty of Medicine, University of Tsukuba, I-I-I Tennodai, Tsukuba, Ibaraki 305 8575, Japan

$\mathrm{Tel} / \mathrm{Fax}+8 \mathrm{I} 298533076$

Email nakata@md.tsukuba.ac.jp
Objective: The objective of this study was to determine the effective dose of an amino acid mixture comprising arginine, alanine, and phenylalanine combined with physical activity promotion in reducing abdominal fat among overweight adults.

Methods: A 12-week randomized, double-blind, placebo-controlled, dose-ranging, pilot trial was conducted in Mito, Japan, from January through April 2016, and the data were analyzed from May through November 2016. The study participants were 35 overweight adults, aged 20-64 years, with no regular exercise habit. Participants were randomly assigned to high-dose $(3,000 \mathrm{mg} / \mathrm{d}$, $\mathrm{n}=9)$, medium-dose $(1,500 \mathrm{mg} / \mathrm{d}, \mathrm{n}=9)$, low-dose $(750 \mathrm{mg} / \mathrm{d}, \mathrm{n}=8)$, or placebo $(0 \mathrm{mg} / \mathrm{d}, \mathrm{n}=9)$ groups, and the test beverage containing the amino acid mixture or placebo was administered for 12 weeks. All participants maintained a physically active lifestyle during the study period through monthly physical activity promotion sessions and smartphone-based self-monitoring with wearable trackers. Primary outcomes were changes in abdominal total, subcutaneous, and visceral fat areas, assessed by computed tomography.

Results: Of the 35 enrolled participants, 32 completed the 12 -week follow-up visit. The intention-to-treat analysis revealed that the changes in abdominal total fat area were $-14.6 \mathrm{~cm}^{2}(95 \%$ confidence interval [CI], $-39.6 \mathrm{~cm}^{2}$ to $\left.10.4 \mathrm{~cm}^{2}\right),-25.3 \mathrm{~cm}^{2}\left(95 \% \mathrm{CI},-71.0 \mathrm{~cm}^{2}\right.$ to $\left.20.3 \mathrm{~cm}^{2}\right)$, $-23.2 \mathrm{~cm}^{2}\left(95 \% \mathrm{CI},-48.0 \mathrm{~cm}^{2}\right.$ to $\left.1.6 \mathrm{~cm}^{2}\right)$, and $-12.5 \mathrm{~cm}^{2}\left(95 \% \mathrm{CI},-29.1 \mathrm{~cm}^{2}\right.$ to $\left.4.0 \mathrm{~cm}^{2}\right)$ in the high-dose, medium-dose, low-dose, and placebo groups, respectively. Similar results were obtained for visceral and subcutaneous fat areas. No study-related adverse events were reported. Conclusion: Compared with placebo, a medium or low dose of the amino acid mixture may facilitate abdominal fat reduction among overweight adults. A larger randomized trial with sufficient statistical power should be implemented to validate the effectiveness of this supplement. Keywords: amino acid mixture, dose-response relationship, physical activity promotion, abdominal fat

\section{Introduction}

As eating habits and lifestyle become more Westernized in Japan, the proportion of obese (defined as body mass index $[\mathrm{BMI}] \geq 25 \mathrm{~kg} / \mathrm{m}^{2}$ ) Japanese has been increasing steadily in recent decades. ${ }^{1}$ According to the National Health and Nutrition Survey conducted in $2015,{ }^{2}$ the prevalence of overweight or obese Japanese adults is $29.5 \%$ in males and $19.2 \%$ in females. Furthermore, among Japanese adults with abdominal obesity, aged 40-74 years, 20 million are estimated to have metabolic abnormalities such as hyperglycemia, dyslipidemia, and hypertension. ${ }^{3}$ This suggests that Japanese 
individuals are susceptible to cardiovascular diseases or other serious complications at even mild levels of overweight.

To prevent and/or mitigate these concerns, weight loss through dietary restriction and regular exercise is considered the best available non-surgical, non-pharmacologic treatment strategy. ${ }^{4}$ Moreover, additive or synergetic effects of diet and exercise have received much attention in recent years. ${ }^{5,6}$ Our team has been studying the effects of amino acids combined with exercise on fat oxidation for the past two decades. ${ }^{7-14}$ We demonstrated that a 12-week administration of a mixture of 17 amino acids combined with regular exercise increased aerobic fitness and reduced abdominal visceral fat in sedentary older women. ${ }^{12}$ We also reported that acute administration of different compositions of 17 amino acids significantly increased maximal blood levels of glycerol and acetoacetic acid during exercise. ${ }^{13}$ Recently, we focused on arginine, alanine, and phenylalanine, which are involved in glucagon synthesis and secretion when administered acutely. We also confirmed that a single session of aerobic exercise combined with an oral arginine, alanine, and phenylalanine mixture (A-mix) increased blood glycerol levels and ketone body levels in humans, compared with placebo. ${ }^{14}$ These findings suggest a lipolytic effect during exercise attributable to ingesting the A-mix.

To our knowledge, no study has evaluated the long-term effectiveness of A-mix ingestion for overweight or obese individuals, and the effective dose of the mixture is unknown. Therefore, the objective of this 12-week pilot trial was to determine the effective dose of oral A-mix, along with its effects when combined with physical activity on abdominal fat reduction in overweight adults aged 20-64 years. The findings from this pilot trial will allow us to design a future trial with a larger sample size to confirm the effectiveness of combining A-mix ingestion with physical activity in overweight adults.

\section{Methods}

\section{Trial design}

This study was a pilot placebo-controlled, double-blind, parallel-group, randomized trial; the trial was conducted at a single site in Mito, Japan, from January through April 2016, and the data were analyzed from May through November 2016. The study protocol was approved by the Institutional Review Board, University of Tsukuba Faculty of Medicine, and the Meiji Institutional Review Board. Each participant provided written informed consent before randomization. The protocol was registered in the UMIN Clinical Trials Registry (UMIN000019870) on November 15, 2015. This article fully complies with the Consolidated Standards of Reporting Trials (CONSORT) 2010 guideline. ${ }^{15} \mathrm{~A}$ data-monitoring committee assured accuracy of data collection and inputs.

\section{Participants}

Participants were recruited via advertisements posted in local newspapers and volunteer databases associated with two contract research organizations. The inclusion criteria were overweight $\left(\mathrm{BMI} \geq 25 \mathrm{but}<30 \mathrm{~kg} / \mathrm{m}^{2}\right.$ ) adults aged $20-64$ years old without regular exercise habits. A regular exercise habit was defined as engaging in at least $30 \mathrm{~min}$ of exercise twice a week for more than 1 year, according to the criteria of the National Health and Nutrition Survey. ${ }^{2}$ The exclusion criteria were individuals with a history or current condition of severe diseases, heavy drinkers ( $\geq 40 \mathrm{~g}$ of ethanol/d), heavy smokers ( $\geq 40$ cigarettes/d), those with extremely irregular eating patterns due to shift work or late-night work, those who were pregnant or breastfeeding or wished to become pregnant during the study period, those who regularly consumed functional foods or nutritional supplements or who had taken them over the past 6 months, patients with phenylketonuria or hyperphenylalaninemia, those who were enrolled in other clinical trials, those who had participated in other clinical trials over the past 6 months, and those who were judged ineligible by the study physician (HK) due to abnormal blood and urine parameters or other reasons.

\section{Randomization and blinding}

After stratifying by sex, eligible participants were randomized to the high-dose, medium-dose, low-dose, or placebo group, with an allocation ratio of 1:1:1:1. A statistician who had no contact with the participants and staff members generated a random number sequence using a validated computer program. The random sequence was kept by a designated person who was in charge of shipping the test beverages to participants, but was not involved in the design, recruitment, assessment, intervention, or analysis. Participants and investigators were blinded to the group assignment. The randomization code was opened after the dataset was carefully checked, cleaned, and fixed.

\section{Interventions}

The test item was a 500-mL PET bottle beverage, containing 3,000 $\mathrm{mg}, 1,500 \mathrm{mg}$, or $750 \mathrm{mg} \mathrm{A-mix} \mathrm{for} \mathrm{the} \mathrm{high-dose,}$ medium-dose, and low-dose groups, respectively; the placebo group received a beverage containing $0 \mathrm{mg}$ A-mix. We recently found increased levels of blood glycerol and ketone body concentrations following a single session of aerobic 
exercise after ingesting 3,000 mg of A-mix. ${ }^{14}$ Based on this finding, we set 3,000 mg/d as the upper limit and geometrically allocated the remaining doses at $1,500 \mathrm{mg}, 750 \mathrm{mg}$, and $0 \mathrm{mg}$. The test beverages had identical appearance and similar sensory characteristics and were, therefore, indistinguishable from each other. The A-mix contained $42 \% \mathrm{~mol} / \mathrm{mol}$ of phenylalanine, $38 \% \mathrm{~mol} / \mathrm{mol}$ of alanine, and $20 \% \mathrm{~mol} / \mathrm{mol}$ of arginine. The calorie counts per bottle in the test beverages were $26 \mathrm{kcal}, 20 \mathrm{kcal}, 17 \mathrm{kcal}$, and $14 \mathrm{kcal}$, for the high-dose, medium-dose, low-dose, and placebo groups, respectively. None of the test beverages contained caffeine. The designated person shipped the test beverages to participants based on group assignment. Participants were instructed to keep the test beverages away from direct sunlight, high temperature, and high humidity, and to consume one bottle per day before and during moderate or vigorous physical activity under free-living conditions.

Irrespective of group assignment, all participants received a physical activity promotion program throughout the 12-week intervention period. The intervention program comprised a combination of monthly group-based physical activity classes with individualized counseling and a remote coaching program for physical activity promotion via smartphone apps. Participants were encouraged to increase 1,000 steps/d or more from their baseline step counts according to the recent physical activity guideline in Japan. ${ }^{16,17}$ Each group-based physical activity class began with 90-min groupbased physical activity sessions, which included walking, muscle-strengthening activity, and stretching, and was followed by 30 -min individualized counseling sessions regarding the timing of daily physical activity and test beverage ingestion. Experienced interventionists led the individualized counseling sessions while reviewing participants' recent step counts, body weight, test beverage ingestion, physical condition, medication use, sleep patterns, dietary habits, and exercise, all of which were recorded in diaries. In the remote coaching program, all participants were provided with a wristband-type activity tracker (Fitbit Flex; Fitbit, San Francisco, CA, USA) and were instructed to monitor daily step counts, to record their body weight using a digital scale at home, and to transmit the information through a semi-customized smartphone app (HealthPlayer; Practechs, Tokyo, Japan). The interventionists reviewed the uploaded information and emailed the participants weekly to encourage physical activity. The smartphone app also displayed the weekly rankings of each participant's step counts up to the top tenth, which was used as a motivation tool for promoting physical activity under unsupervised home settings. To avoid the confounding effects of lifestyle changes, participants were instructed to consume well-balanced meals three times per day according to the Japanese Food Guide Spinning Top ${ }^{18}$ and to refrain from excessively strenuous exercise, binge eating, severe energy restriction, or consumption of nutritional supplements, functional foods, and over-the-counter drugs that could potentially affect study outcomes.

\section{Measurements}

All study outcomes were measured at baseline and during a 12-week follow-up visit by trained staff members who were blinded to the group assignment. Primary outcome measures were changes in abdominal fat areas. Secondary outcomes included changes in body weight, waist circumference, total and regional body composition, and metabolic risk factors such as blood pressure, lipid profiles, and blood glucose parameters. Compliance outcomes, ie, dietary intake and physical activity, were also measured at baseline and on week 12 .

\section{Anthropometrics}

Body weight was measured to the nearest $0.05 \mathrm{~kg}$ using a calibrated digital scale (WB-150; Tanita, Tokyo, Japan). Height was measured to the nearest $0.1 \mathrm{~cm}$ using a portable stadiometer (213; Seca, Hamburg, Germany) at baseline to estimate BMI. BMI was computed as weight in kilograms divided by squared height in meters. Waist circumference was measured twice to the nearest $0.1 \mathrm{~cm}$ at the umbilicus using a flexible plastic tape in the standing position. The averaged value of the two measurements was used for data analysis.

\section{Abdominal fat areas and body composition}

Abdominal fat areas were scanned at the level of the umbilicus using computed tomography (ECLOS; Hitachi Healthcare Manufacturing, Tokyo, Japan) in the supine position and were calculated using a validated commercial software program (FatScan; N2system, Osaka, Japan). ${ }^{19}$ Total and regional body composition was quantified using multifrequency bioelectrical impedance analysis (InBody 430; Biospace, Seoul, Korea). ${ }^{20}$

\section{Blood pressure readings}

Systolic and diastolic blood pressure readings were taken with an automated sphygmomanometer (HEM-7430; Omron Healthcare, Kyoto, Japan) on the arm of seated participants who had rested for at least $5 \mathrm{~min}$ with the arm supported at heart level. The average value of the two readings was used for data analysis. 


\section{Blood biochemistry}

A blood sample was drawn from each participant after an overnight $(\geq 12$ h) fast. Serum total cholesterol and triglycerides were determined enzymatically (Determiner L TG II; Kyowa Medex Co., Ltd., Tokyo, Japan). Serum high-density lipoprotein cholesterol was measured by selective inhibition method (MetaboLead HDL-C; Kyowa Medex Co., Ltd.). Serum low-density lipoprotein cholesterol was estimated according to the Friedewald equation (total cholesterol $[\mathrm{mg} / \mathrm{dL}]$ - high-density lipoprotein cholesterol $[\mathrm{mg} / \mathrm{dL}]$ - triglyceride $[\mathrm{mg} / \mathrm{dL}] / 5) .{ }^{21}$ Blood glucose was assayed by hexokinase-G-6-PDH method (L-Type Glu 2; Wako Pure Chemical Industries, Ltd., Osaka, Japan), and insulin was measured by electrochemiluminescence immunoassay method (ECLusys Insulin; Roche Diagnostics, Tokyo, Japan). Glycated hemoglobin A (HbA1c) was determined by latex agglutination method (Determiner L HbA1c; Kyowa Medex Co., Ltd.). Venous blood was assayed by an independent laboratory (Kotobiken Medical Laboratories, Ibaraki, Japan).

\section{Dietary intake}

Total energy intake, in kilocalories, and macronutrient intake, in grams, were assessed by 3-day weighed food records. Participants were asked to record everything they consumed for 3 days, including 2 weekdays and 1 weekend day. Foods were measured using standard measuring cups, spoons, and digital scales. To ensure overall comparability, a skilled nutritionist who was blinded to the group assignment analyzed all food records.

\section{Physical activity}

Physical activity was measured with a validated triaxial accelerometer (Active style Pro HJA-750C; Omron Healthcare) at the waist for 14 days. The accelerometer counted daily steps, estimated the intensity of physical activity (expressed as metabolic equivalents [METs]), and classified locomotive or nonlocomotive activities with a validated algorithm. ${ }^{22,23}$ The devices were not worn when sleeping, while engaged in a water-based activity (eg, bathing or swimming), or while participating in activities such as contact sports for safety reasons. Records obtained were defined as valid when a device was worn for at least $10 \mathrm{~h} / \mathrm{d} .{ }^{24}$ When valid records were collected for more than 3 days, daily step counts, times spent in moderate-to-vigorous physical activity (MVPA, $\geq 3$ METs), and locomotive and nonlocomotive MVPA were calculated for each participant.

\section{Sociodemographic and lifestyle variables}

Participants also reported sociodemographic and lifestyle characteristics via self-administered questionnaires at baseline. Characteristics included education (whether a college graduate or not), household income ( $\geq$ or $<5,000,000$ yen [equivalent to 44,000 USD]), current marriage status (married or unmarried), and current smoking and drinking habits (yes or no for both).

\section{Adverse events and success of blinding}

Adverse events were subjectively reported through participants' diaries and were objectively collected using blood pressure readings and blood hematological and biochemical tests. In this trial, an adverse event was defined as any unfavorable and unintended sign, symptom, or disease temporarily associated with the ingestion of the test beverage, without any judgment about causality. The study physician (HK) judged whether a given adverse event was serious or non-serious, as well as whether study related or not. Participants reported a guess on their own group assignment on a post-intervention survey. The response was used to assess whether blinding was successful or not.

\section{Statistical analysis}

We set the target number of participants at 80 (ie, 20 participants in each group). Since this was a pilot trial, there was no statistical basis for this sample size setting. However, a sample size of 20 participants per group allowed us to detect between-group difference of effect size of 0.9 (Cohen's d) with a significance level of $5 \%$ and a detection power of $80 \%$. Assuming that some would decline to participate in the trial or not meet eligibility criteria, a target number of 100 adults was set for the orientation session.

All statistical analyses were performed in full accordance with the analysis plan in the study protocol, using the opensource statistical environment R (3.2.4 for Windows 64-bit). A $p$-value $<0.05$ was considered statistically significant. Baseline participant characteristics are presented as mean and standard deviation for continuous variables or frequency and percentage for categorical variables. Our primary analysis was based on an intention-to-treat (ITT) principle, with missing data replaced by baseline observations carried forward. Primary, secondary, and compliance outcomes are presented with mean and $95 \%$ confidence interval (CI). Next, one-way analysis of variance with Dunnett's post hoc test was employed to examine betweengroup differences.

The secondary analysis followed a per-protocol-based (PPB) principle, where we excluded those who met at least one of the following prespecified criteria: 1) missed the 12-week follow-up visit, 2) low compliance rate $(<80 \%)$ with consumption of the test beverages, 3) missing or incomplete diary logs, 4) declared ineligible after randomization, and 5) serious violation of study compliance judged by the principal investigator (YN) and the study physician (HK). Adverse events were also compared among the four groups using one-way analysis of variance for 
continuous variables and chi-squared tests for categorical variables. To assess the success of blinding, percentages of those who correctly identified their group assignment were calculated and compared among the four groups using chi-squared tests.

\section{Results}

The complete flowchart of the study participants is presented in Figure 1. We faced unexpected difficulties in recruiting participants and eventually invited 53 candidates to the orientation session. Of those invited, 43 adults attended the orientation session and gave written informed consent, and 42 completed a baseline examination. Of these, 35 met the eligibility criteria and were randomly assigned to the high-dose $(n=9)$, mediumdose $(n=9)$, low-dose $(n=8)$, and placebo groups $(n=9)$. The 35 randomized participants were subject to the ITT analysis.
Baseline participant characteristics are presented in Table 1. There were no notable differences in sociodemographic and lifestyle variables or any other study outcomes between the four groups. Of the 35 participants, 32 (91.4\%) completed the 12-week follow-up visit. Two participants dropped out from the trial for personal reasons and one was excluded after missing the 12-week visit. Among the 32 who completed the trial, the median rate of test beverage intake was $95.2 \%(65.5 \%-100.0 \%)$ with no between-group differences $(p=0.86)$. After excluding four additional participants (one participant in each group) with low compliance of test beverage ingestion $(<80 \%), 28$ participants were included in the PPB analysis. Apart from those who missed the 12-week visit, there were five participants with missing data for the weighed dietary intake $(n=1)$ and physical activity $(\mathrm{n}=4)$ at week 12 .

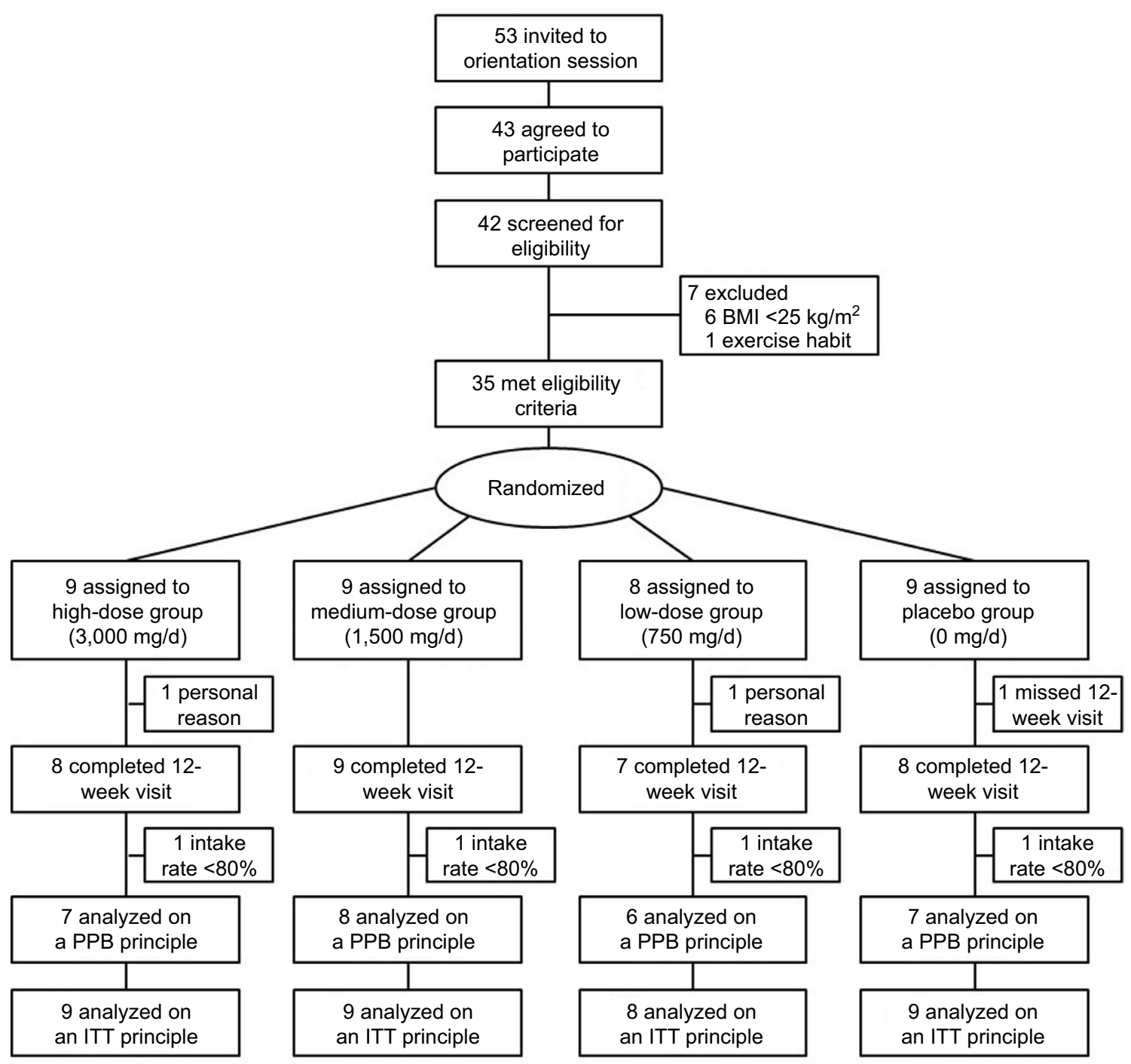

Figure I Flowchart of study participants.

Abbreviations: BMI, body mass index; ITT, intention to treat; PPB, per protocol based. 
Table I Baseline participant characteristics

\begin{tabular}{|c|c|c|c|c|}
\hline & $\begin{array}{l}\text { High-dose group } \\
(3,000 \mathrm{mg} / \mathrm{d}, \mathrm{n}=9)\end{array}$ & $\begin{array}{l}\text { Medium-dose group } \\
(1,500 \mathrm{mg} / \mathrm{d}, \mathrm{n}=9)\end{array}$ & $\begin{array}{l}\text { Low-dose group } \\
(750 \mathrm{mg} / \mathrm{d}, \mathrm{n}=8)\end{array}$ & $\begin{array}{l}\text { Placebo group } \\
(0 \mathrm{mg} / \mathrm{d}, \mathrm{n}=9)\end{array}$ \\
\hline Female, No. (\%) & $4(44.4)$ & $5(55.6)$ & $4(50.0)$ & $4(44.4)$ \\
\hline Age, years & $44.3(9.4)$ & $39.7(8.0)$ & $41.9(10.5)$ & $46.4(9.4)$ \\
\hline College/university graduates, No. (\%) & $6(66.7)$ & $5(55.6)$ & $5(62.5)$ & $4(44.4)$ \\
\hline Household income $(\$ 50,000+)$, No. $(\%)$ & $5(55.6)$ & $4(44.4)$ & $6(75.0)$ & $5(55.6)$ \\
\hline Married, No. (\%) & $6(66.7)$ & $6(66.7)$ & $5(62.5)$ & $7(77.8)$ \\
\hline Current cigarette smoking, No. (\%) & $2(22.2)$ & $0(0.0)$ & I (I2.5) & I (II.I) \\
\hline Current alcohol drinking, No. (\%) & $6(66.7)$ & $8(88.9)$ & $4(50.0)$ & $4(44.4)$ \\
\hline Height, $\mathrm{cm}$ & $165.9(7.8)$ & $166.8(10.5)$ & $164.6(11.0)$ & $161.9(9.4)$ \\
\hline Weight, kg & $75.8(9.6)$ & $76.4(13.4)$ & $72.5(12.1)$ & $71.0(9.1)$ \\
\hline Body mass index, $\mathrm{kg} / \mathrm{m}^{2}$ & $27.4(1.3)$ & $27.2(1.6)$ & $26.6(1.4)$ & $27.0(1.0)$ \\
\hline Waist circumference, $\mathrm{cm}$ & $93.8(4.0)$ & $95.3(7.7)$ & $93.4(8.8)$ & $95.0(5.8)$ \\
\hline \multicolumn{5}{|l|}{ Abdominal fat area, $\mathrm{cm}^{2}$} \\
\hline Total & $300.1(45.6)$ & $340.0(68.9)$ & $326.3(114.8)$ & $357.2(71.7)$ \\
\hline Subcutaneous & $197.8(37.8)$ & $232.5(39.5)$ & | $96.1(38.2)$ & $231.4(70.7)$ \\
\hline Visceral & $102.3(44.0)$ & $107.5(50.0)$ & $130.2(99.6)$ & $125.8(32.6)$ \\
\hline Fat mass, kg & $22.8(4.4)$ & $23.8(3.7)$ & $22.8(4.0)$ & $24.5(4.2)$ \\
\hline Fat-free mass, $\mathrm{kg}$ & $49.9(10.1)$ & $49.6(10.6)$ & $47.0(8.9)$ & $44.0(7.6)$ \\
\hline \multicolumn{5}{|l|}{ Fat mass, $\%$} \\
\hline Total & $30.6(7.0)$ & $31.5(4.1)$ & $31.6(3.7)$ & $34.6(5.3)$ \\
\hline Right arm & $33.9(11.2)$ & $35.5(5.6)$ & $34.6(5.6)$ & $38.4(7.2)$ \\
\hline Left arm & $34.2(11.7)$ & $35.6(5.4)$ & $35.8(5.7)$ & $39.0(7.1)$ \\
\hline Trunk & $32.4(6.3)$ & $33.4(3.4)$ & $33.3(3.2)$ & $35.8(4.5)$ \\
\hline Right leg & $28.5(7.0)$ & $29.1(4.2)$ & $29.5(4.3)$ & $32.2(5.5)$ \\
\hline Left leg & $28.5(7.1)$ & $29.1(4.3)$ & $29.2(4.1)$ & $32.3(5.3)$ \\
\hline \multicolumn{5}{|l|}{ Blood pressure, $\mathrm{mmHg}$} \\
\hline Systolic & $134.3(16.8)$ & I38.9 (22.4) & I30.5 (I4.7) & $127.3(15.0)$ \\
\hline Diastolic & $85.0(9.9)$ & $86.6(11.5)$ & $82.4(12.5)$ & $82.1(9.1)$ \\
\hline \multicolumn{5}{|l|}{ Blood biochemical parameters } \\
\hline Triglycerides, mg/dL & $130.0(66.4)$ & | 46.7 (107.I) & I33.4 (I06.8) & $150.7(97.6)$ \\
\hline Total cholesterol, mg/dL & $210.7(36.9)$ & $218.7(35.8)$ & $192.8(20.9)$ & $253.6(55.7)$ \\
\hline HDL cholesterol, mg/dL & $57.0(20.9)$ & $56.2(9.6)$ & $54.4(20.6)$ & $49.0(I I . I)$ \\
\hline LDL cholesterol, mg/dL & $132.9(30.5)$ & $137.9(38.1)$ & $116.4(17.6)$ & $176.1(47.3)$ \\
\hline Fasting blood glucose, $\mathrm{mg} / \mathrm{dL}$ & $91.6(7.2)$ & $91.8(7.5)$ & $94.5(13.6)$ & $97.2(10.9)$ \\
\hline Glycated hemoglobin Alc, \% & $5.43(0.23)$ & $5.29(0.29)$ & $5.62(0.89)$ & $5.56(0.35)$ \\
\hline Fasting insulin, IU & $9.1(3.1)$ & $17.2(14.9)$ & $9.6(4.0)$ & $17.3(2 \mid .7)$ \\
\hline \multicolumn{5}{|l|}{ Dietary intake } \\
\hline Total energy, kcal/d & $2,361(539)$ & $1,998(383)$ & $2,216(420)$ & $2,212(938)$ \\
\hline Protein, g/d & $83.9(14.3)$ & $69.6(9.8)$ & $86.5(25.4)$ & $79.7(30.0)$ \\
\hline Fat, g/d & $85.9(28.5)$ & $66.6(15.9)$ & $73.0(10.5)$ & $85.3(59.8)$ \\
\hline Carbohydrate, g/d & $295.9(57.6)$ & $268.7(71.6)$ & $282.1(58.6)$ & $266.8(92.9)$ \\
\hline \multicolumn{5}{|l|}{ Physical activity } \\
\hline Daily step counts, steps/d & $5,611(3,484)$ & $6,974(2,882)$ & $6,172(2,786)$ & $6,327(3,121)$ \\
\hline MVPA, $\min / d$ & $53.7(32.5)$ & $67.6(36.4)$ & $49.3(17.2)$ & $59.1(33.6)$ \\
\hline Locomotive MVPA, $\mathrm{min} / \mathrm{d}$ & $26.7(22.5)$ & $34.4(29.4)$ & $30.6(16.0)$ & $29.1(23.9)$ \\
\hline Non-locomotive MVPA, $\mathrm{min} / \mathrm{d}$ & $26.9(26.2)$ & $33.2(35.1)$ & $18.7(9.3)$ & $29.9(25.5)$ \\
\hline
\end{tabular}

Notes: Data shown as mean (standard deviation) unless specified.

Abbreviation: HDL, high-density lipoprotein; LDL, low-density lipoprotein; MVPA, moderate-to-vigorous physical activity.

The ITT analysis in Table 2 shows that the changes in abdominal total fat area were $-14.6 \mathrm{~cm}^{2},-25.3 \mathrm{~cm}^{2},-23.2 \mathrm{~cm}^{2}$, and $-12.5 \mathrm{~cm}^{2}$ in the high-dose, medium-dose, low-dose, and placebo groups, respectively. Changes in abdominal visceral fat area were $-5.4 \mathrm{~cm}^{2},-12.0 \mathrm{~cm}^{2},-13.5 \mathrm{~cm}^{2}$, and $-4.7 \mathrm{~cm}^{2}$ in the high-dose, medium-dose, low-dose, and placebo groups, respectively. Similar results were obtained for the change in abdominal subcutaneous fat area. Although significant differences in diastolic blood pressure and $\mathrm{HbAlc}$ were observed in the four groups, Dunnett's post hoc test detected no significant differences from the placebo group. No significant between-group differences were found for any of the primary and secondary outcomes. As for the compliance outcome measures, daily total energy intake increased slightly by $18.4 \mathrm{kcal}$ in the high-dose 
Table 2 Intention-to-treat analyses for primary, secondary, and compliance outcomes $(n=35)$

\begin{tabular}{|c|c|c|c|c|c|}
\hline & $\begin{array}{l}\text { High-dose group } \\
(3,000 \mathrm{mg} / \mathrm{d} \text {, } \\
\mathrm{n}=9)\end{array}$ & $\begin{array}{l}\text { Medium-dose } \\
\text { group }(1,500 \\
\mathrm{mg} / \mathrm{d}, \mathrm{n}=9)\end{array}$ & $\begin{array}{l}\text { Low-dose group } \\
(750 \mathrm{mg} / \mathrm{d}, \mathrm{n}=8)\end{array}$ & $\begin{array}{l}\text { Placebo group } \\
(0 \mathrm{mg} / \mathrm{d}, \mathrm{n}=9)\end{array}$ & $\begin{array}{l}p \text {-value } \\
\text { for } \\
\text { ANOVA }\end{array}$ \\
\hline \multicolumn{6}{|l|}{ Primary outcomes } \\
\hline \multicolumn{6}{|l|}{ Abdominal fat area, $\mathrm{cm}^{2}$} \\
\hline Total & $-14.6(-39.6,10.4)$ & $-25.3(-71.0,20.3)$ & $-23.2(-48.0,1.6)$ & $-12.5(-29.1,4.0)$ & 0.87 \\
\hline Subcutaneous & $-9.3(-23.3,4.8)$ & $-13.3(-47.2,20.6)$ & $-9.7(-25.3,5.9)$ & $-7.9(-20.2,4.5)$ & 0.98 \\
\hline Visceral & $-5.4(-20.6,9.8)$ & $-12.0(-26.0,2.0)$ & $-13.5(-32.1,5.1)$ & $-4.7(-14.6,5.2)$ & 0.67 \\
\hline \multicolumn{6}{|l|}{ Secondary outcomes } \\
\hline Weight, kg & $-0.87(-2.23,0.49)$ & $-1.32(-5.20,2.56)$ & $-1.04(-2.63,0.56)$ & $-0.33(-1.57,0.91)$ & 0.91 \\
\hline Waist circumference, $\mathrm{cm}$ & $-1.58(-3.10,-0.05)$ & $-0.70(-4.55,3.15)$ & $-1.39(-2.96,0.18)$ & $-0.23(-1.98,1.52)$ & 0.78 \\
\hline Fat mass, $\mathrm{kg}$ & $-0.29(-1.58,1.00)$ & $-1.36(-3.35,0.64)$ & $-1.53(-3.13,0.08)$ & $-0.63(-1.84,0.57)$ & 0.53 \\
\hline Fat-free mass, kg & $-0.46(-1.50,0.59)$ & $0.10(-1.87,2.07)$ & $0.41(-0.56,1.38)$ & $0.22(-0.31,0.75)$ & 0.71 \\
\hline \multicolumn{6}{|l|}{ Fat mass, $\%$} \\
\hline Total & $-0.03(-1.42,1.36)$ & $-1.31(-2.83,0.21)$ & $-1.71(-3.69,0.27)$ & $-0.60(-1.67,0.47)$ & 0.28 \\
\hline Right arm & $-0.03(-2.20,2.13)$ & $-1.96(-3.67,-0.24)$ & $-2.50(-4.97,-0.03)$ & $-1.06(-2.24,0.13)$ & 0.19 \\
\hline Left arm & $0.28(-2.09,2.65)$ & $-1.62(-3.11,-0.13)$ & $-2.70(-5.23,-0.17)$ & $-0.97(-2.22,0.29)$ & 0.11 \\
\hline Trunk & $-0.12(-1.57,1.33)$ & $-1.37(-2.89,0.16)$ & $-1.74(-3.79,0.31)$ & $-0.57(-1.50,0.37)$ & 0.30 \\
\hline Right leg & $-0.03(-1.24,1.18)$ & $-0.99(-2.27,0.29)$ & $-1.54(-3.22,0.14)$ & $-0.58(-1.54,0.38)$ & 0.29 \\
\hline Left leg & $-0.07(-1.32,1.18)$ & $-1.04(-2.26,0.17)$ & $-1.48(-3.12,0.17)$ & $-0.67(-1.65,0.31)$ & 0.34 \\
\hline \multicolumn{6}{|l|}{ Blood pressure, $\mathrm{mmHg}$} \\
\hline Systolic & $-6.17(-10.12,-2.21)$ & $3.94(-3.24,11.13)$ & $-3.56(-9.06,1.93)$ & $-1.89(-8.53,4.76)$ & 0.06 \\
\hline Diastolic & $-7.67(-12.71,-2.63)$ & $0.17(-3.65,3.98)$ & $-3.31(-6.49,-0.14)$ & $-2.44(-6.74,1.85)$ & 0.03 \\
\hline \multicolumn{6}{|l|}{ Blood biochemical parameters } \\
\hline Triglycerides, mg/dL & $-23.6(-69.6,22.5)$ & $6.6(-76.8,89.9)$ & $-24.9(-70.6,20.8)$ & $-2.9(-33.9,28.1)$ & 0.74 \\
\hline Total cholesterol, mg/dL & $-17.0(-35.1,1.1)$ & $-14.9(-29.0,-0.7)$ & $-11.6(-27.8,4.6)$ & $-10.6(-20.9,-0.2)$ & 0.89 \\
\hline HDL cholesterol, mg/dL & $-6.33(-14.91,2.24)$ & $-4.00(-9.24,1.24)$ & $1.50(-4.85,7.85)$ & $-1.11(-4.15,1.93)$ & 0.20 \\
\hline LDL cholesterol, mg/dL & $-11.8(-27.5,4.0)$ & $-14.0(-28.3,0.3)$ & $-12.0(-27.2,3.2)$ & $-9.4(-16.5,-2.4)$ & 0.96 \\
\hline Fasting blood glucose, $\mathrm{mg} / \mathrm{dL}$ & $0.00(-5.64,5.64)$ & $0.67(-2.75,4.08)$ & $2.38(-11.35,16.10)$ & $0.33(-3.82,4.49)$ & 0.96 \\
\hline Glycated hemoglobin Alc, \% & $-0.02(-0.12,0.08)$ & $0.00(-0.07,0.07)$ & $0.14(0.01,0.26)$ & $0.09(-0.01,0.19)$ & 0.04 \\
\hline Fasting insulin, IU & $0.37(-1.86,2.59)$ & $-5.54(-15.23,4.14)$ & $-0.61(-4.49,3.26)$ & $0.43(-2.43,3.30)$ & 0.26 \\
\hline \multicolumn{6}{|l|}{ Compliance measures } \\
\hline \multicolumn{6}{|l|}{ Dietary intake } \\
\hline Total energy, kcal/d & $18.4(-389.7,426.6)$ & $25.0(-510.1,560.1)$ & $-171.5(-442.1,99.1)$ & $-372.0(-846.1,102.1)$ & $0.4 \mathrm{I}$ \\
\hline Protein, g/d & $1.4(-10.9,13.7)$ & $3.0(-17.1,23.1)$ & $-12.0(-27.4,3.4)$ & $-11.9(-21.2,-2.6)$ & 0.20 \\
\hline Fat, g/d & $-3.1(-20.7,14.5)$ & $-0.9(-19.3,17.5)$ & $2.3(-11.7,16.2)$ & $-25.7(-70.0,18.7)$ & 0.33 \\
\hline Carbohydrate, g/d & | $3.8(-6 \mid .7,89.2)$ & $-4.3(-70.7,62.0)$ & $-39.1(-79.0,0.9)$ & $-17.9(-44.7,8.9)$ & 0.50 \\
\hline \multicolumn{6}{|l|}{ Physical activity } \\
\hline Daily step counts, steps/d & $1,854(-1,538,5,246)$ & $196(-1,749,2,142)$ & $2,518(-670,5,706)$ & $284(-152,720)$ & 0.35 \\
\hline MVPA, $\min / d$ & $12.6(-17.1,42.2)$ & $-4.9(-21.8,12.1)$ & $22.5(-4.5,49.5)$ & $2.6(-6.8,11.9)$ & 0.22 \\
\hline Locomotive MVPA, min/d & $13.8(-15.1,42.6)$ & $-1.0(-13.7,11.6)$ & $18.6(-5.0,42.2)$ & $5.0(-3.8,13.7)$ & 0.40 \\
\hline Non-locomotive MVPA, $\mathrm{min} / \mathrm{d}$ & $-1.22(-9.23,6.79)$ & $-3.83(-12.99,5.32)$ & $3.92(-1.96,9.79)$ & $-2.43(-6.4 I, I .54)$ & 0.35 \\
\hline
\end{tabular}

Notes: Data shown as mean ( $95 \%$ confidence intervals).

Abbreviations: ANOVA, analysis of variance; HDL, high-density lipoprotein; LDL, low-density lipoprotein; MVPA, moderate-to-vigorous physical activity.

group and $25.0 \mathrm{kcal}$ in the medium-dose group, and decreased by $171.5 \mathrm{kcal}$ in the low-dose group and $372.0 \mathrm{kcal}$ in the placebo group. Daily step counts increased by 1,854, 196, 2,518, and 284, in the high-dose, medium-dose, low-dose, and the placebo groups, respectively. There were no significant differences in any of the study compliance outcomes among the four groups. The PPB analysis $(\mathrm{n}=28)$ also demonstrated no between-group differences in any of the study outcomes (Table S1).
No serious adverse events were reported throughout the trial. A total of 34 non-serious adverse events were reported through participants' diaries (Table S2). These events included fever, headache, toothache, bodily pains, and common gastroenterological symptoms such as diarrhea and constipation. Similarly, 29 abnormal signs (ie, out of the reference range) were newly identified through blood pressure readings and fasting blood tests conducted at week 12 (Table S3). There were no between-group 
differences in any of the identified adverse events, none of which were judged study related by the study physician (HK). Among those who completed the 12-week visit $(n=32)$, the numbers (percentage) of participants who correctly identified their own group assignment were $0(0 \%), 2$ (22.2\%), 2 (28.6\%), and $2(25.0 \%)$ in the high-dose, medium-dose, low-dose, and placebo groups, respectively. No between-group differences were found $(p=0.46)$.

\section{Discussion}

The objective of the study was to determine an effective dose of A-mix combined with physical activity promotion in reducing abdominal fat among overweight adults. We found a trend for larger reductions in abdominal fat area in the medium-dose and low-dose groups, compared with the placebo group. This finding could be applicable to other body composition outcomes. From a safety perspective, no serious or study-related adverse events were identified throughout the study. Although common gastroenterological symptoms and some abnormal ranges of blood biochemistry were identified, these adverse events occurred independent of group assignment (ie, A-mix doses).

The relatively large reduction in abdominal fat in the medium-dose and low-dose groups could be explained by the following physiological mechanisms. A previous study ${ }^{14} \mathrm{dem}-$ onstrated that pre-exercise ingestion of A-mix increased blood concentrations of adrenaline and glucagon during and postexercise. Aerobic exercise leads to a fall in serum insulin and a rise in glucagon concentrations, which protect against a severe decline in blood glucose levels. Gannon and Nuttall reported that specific amino acids such as arginine can stimulate glucagon secretion. ${ }^{25}$ Therefore, reduction in blood glucose by exercise and a transient increase in blood amino acid levels by ingestion may stimulate pancreatic alpha cells and promote glucagon secretion. Furthermore, previous reports have noted that several widely divergent effects of adrenaline and glucagon appear to be mediated by a common effector, adenosine $3^{\prime}, 5^{\prime}$-cyclic monophosphate (cAMP). ${ }^{26}$ The best-known mechanism mediating lipolysis is the cAMP pathway, wherein increased levels of cAMP activate cAMP-dependent protein kinase A (PKA). In this pathway, hormone-sensitive lipase (HSL) is phosphorylated by PKA and then translocates from the cytoplasm to the lipid droplet surface, where it interacts with perilipin A, the result of which is a subsequent release of free fatty acids. ${ }^{27,28} \mathrm{HSL}$ is the most important lipase in lipolysis and is subject to hormonal regulation. ${ }^{29}$ In addition to HSL, adipose triglyceride lipase is expressed predominantly in adipose tissue and is considered the rate-limiting lipolytic enzyme in adipocytes. ${ }^{30,31}$ Therefore, an additional effect by A-mix supplementation combined with physical activity may stimulate the cAMP-dependent cascade pathway. Previous in vitro studies in human cells found that lipolytic responses to adrenalin in visceral adipocytes are 1.5-3.0 times higher than the responses in subcutaneous adipocytes. ${ }^{32,33}$ Therefore, abdominal fat tissues are one target of the exerciseinduced lipolysis. c-AMP-dependent lipolysis may, therefore, increase following acute administration of A-mix combined with exercise, and the accumulated effects may have reduced abdominal fat in the current study.

The reasons for the relative ineffectiveness of the high dose remain unknown. One possible explanation may be an insufficiently robust point estimate of the primary outcomes due to small sample size. The placebo and the high-dose groups showed similar reductions in abdominal fat areas. This may be explained by greater reduction in energy intake $(-372 \mathrm{kcal} / \mathrm{d})$ in the placebo group.

Of the secondary outcomes, changes in diastolic blood pressure and HbA1c significantly differed among the four groups (Table 2). However, neither dose-response relationships nor significant differences from the placebo group were found for the two outcomes. In a future large-scale trial, we should assess whether A-mix ingestion combined with physical activity improves blood pressure and glycemic control.

Compliance measures in dietary intake and physical activity differed among the four groups. Energy intake increased slightly in the high-dose and medium-dose groups, but decreased in the low-dose and placebo groups. The increases in step counts were greater in the high-dose and low-dose groups. Participants in the low-dose group showed reduced energy intake and increased step counts, suggesting substantial energy deficits compared with the other three groups. Therefore, a dose of 1,500 mg/d, which was used in the medium-dose group, may be a reasonable choice for a future larger trial.

In this trial, no serious or study-related adverse events occurred and no dose-dependent relationship was identified. Most of the adverse events were common gastroenterological and neurological symptoms, along with bodily pain. These symptoms frequently occurred following beverage intake in general and exercise, especially for previously inactive individuals. Therefore, the A-mix doses used in this trial are less likely to create serious safety concerns over long-term ingestion.

Our study has several noteworthy strengths. 1) This trial adopted the research design of a placebo-controlled, doubleblind, parallel-group, randomized trial. The post-intervention survey showed the success of blinding to participants, suggesting a low risk of bias in this trial. Therefore, the findings are highly reliable. 2) Abdominal fat areas, as primary outcomes, were assessed by computed tomography, which is regarded as a gold 
standard in evaluating abdominal fat. 3) The study provided a physical activity promotion intervention designed to encourage participants to add $\sim 1,000$ daily steps. This type of mild intervention, rather than a strictly supervised exercise program, can be easily adopted by the general population. ${ }^{17,18} 4$ ) The study had a high retention rate of $91 \%$.

In contrast, we must also note some limitations. 1) The number of enrolled participants was 35 , much lower than the target number of 80 . Therefore, the data robustness may not be high. 2) Despite careful instructions on dietary habits and other lifestyle factors, changes in compliance outcomes such as total and macronutrient intake and daily physical activity differed in the four study groups. These between-group differences in compliance outcomes were not significant, but they may have affected the study results.

\section{Conclusion}

A low or medium dose of the amino acid mixture may facilitate abdominal fat reduction among overweight adults. A larger randomized trial using A-mix doses of 750 or $1,500 \mathrm{mg} / \mathrm{d}$ with sufficient statistical power should be implemented to validate the effectiveness of this supplement.

\section{Acknowledgments}

This trial was based on a collaborative research agreement between the University of Tsukuba Faculty of Medicine and Meiji Co., Ltd. We acknowledge Mr Takuya Nagai who produced and provided the test beverages used in this trial, Mr Akio Tanaka who was in charge of shipping the test beverages to the study participants, Dr Keiko Fujie who generated randomization codes and created an allocation table, Dr Koichi Hashimoto who was in charge of managing participants' personal identification information, and Ms Yuriko Sakairi who provided administrative support and her technical expertise in the data collection. We also gratefully acknowledge the contribution of all the trial staff.

\section{Author contributions}

Study concept and design: KU, CS, SI, and YN; intervention: HS, TT, and YN; data acquisition: all authors; statistical analysis: HS and YN; interpretation: HS and YN; writing the first draft: HS and KU; significant revision: all authors; study physician: $\mathrm{HK}$; overall supervision as a principal investigator: $\mathrm{YN}$.

\section{Disclosure}

KU, CS, and SI are employees of Meiji Co., Ltd. The authors report no other conflicts of interest in this work.

\section{References}

1. Nishi N. Monitoring obesity trends in Health Japan 21. J Nutr Sci Vitaminol (Tokyo). 2015;61(Suppl):S17-S19.

2. Ministry of Health, Labour and Welfare. Report on National Health and Nutrition Survey 2015. Available from: http://www.mhlw.go.jp/bunya/ kenkou/eiyou/dl/h27-houkoku.pdf. Accessed March 27, 2017.

3. Ministry of Health, Labour and Welfare. Report on National Health and Nutrition Survey 2006. Available from: http://www.mhlw.go.jp/houdou/2008/04/d1/h0430-2c.pdf. Accessed March 27, 2017.

4. Jensen MD, Ryan DH,Apovian CM, et al; American College of Cardiology/ American Heart Association Task Force on Practice Guidelines; Obesity Society. 2013 AHA/ACC/TOS guideline for the management of overweight and obesity in adults: a report of the American College of Cardiology/ American Heart Association Task Force on Practice Guidelines and the Obesity Society. Circulation. 2014;129(25 Suppl 2):S102-S138.

5. Kim HK, Suzuki T, Saito K, Yoshida H, Kobayashi H, Kato H, Katayama M. Effects of exercise and amino acid supplementation on body composition and physical function in community-dwelling elderly Japanese sarcopenic women: a randomized controlled trial. JAm Geriatr Soc. 2012; 60(1):16-23.

6. Michishita T, Kobayashi S, Katsuya T, Ogihara T, Kawabuchi K. Evaluation of the antiobesity effects of an amino acid mixture and conjugated linoleic acid on exercising healthy overweight humans: a randomized, double-blind, placebo-controlled trial. J Int Med Res. 2010;38(3):844-859.

7. Abe T, Takiguchi Y, Tamura M, Shimura J, Yamazaki K-I. Effect of vespa amino acid mixture (VAAM) isolated from hornet larval saliva and modified VAAM nutrients on endurance exercise in swimming mice-improvement in performance and changes of blood lactate and glucose. Jpn J Phys Fitness Sports Med. 1995;44(2):225-238.

8. Abe T, Inamori M, Iida K, Tamura M, Takiguchi Y, Yasuda K. The activation of fatty acid metabolism by vespa amino acid mixture (VAAM) and related nutrients during endurance exercise in mice. Adv Exerc Sports Physiol. 1997;3(1):35-44.

9. Tsuchita H, Shirai-Morishita Y, Shimizu T, Abe T. Effects of a vespa amino acid mixture identical to hornet larval saliva on the blood biochemical indices of running rats. Nutr Res. 1997;17(6):999-1012.

10. Mizuno K, Asano K, Abe T, Morishita K. [Effects of ingestion of hornet larval salivary amino acid mixture (HLSA) on metabolic responses during exercise]. Sci Fatigue Rest. 1997;12(1):31-41. Japanese.

11. Saito S, Tsuchita H, Mukai N, Abe T. [Effects of ingestion of vespa amino acid mixture (VAAM) under postprandial conditions on blood ketone body concentrations during prolonged exercise in humans]. Bull Inst Health Sport Sci Univ Tsukuba. 2001;24:71-78. Japanese.

12. Sasai H, Matsuo T, Fujita M, Saito M, Tanaka K. Effects of regular exercise combined with ingestion of vespa amino acid mixture on aerobic fitness and cardiovascular disease risk factors in sedentary older women: a preliminary study. Geriatr Gerontol Int. 2011;11(1):24-31.

13. Ueda K, Nakamura Y, Yamaguchi M, Mori T, Uchida M, Fujita S. Amino acid mixture enriched with arginine, alanine, and phenylalanine stimulates fat metabolism during exercise. Int J Sport Nutr Exerc Metab. 2016;26(1):46-54.

14. Ueda K, Sanbongi C, Takai S, Ikegami S, Fujita S. Combination of aerobic exercise and an arginine, alanine, and phenylalanine mixture increases fat mobilization and ketone body synthesis. Biosci Biotechnol Biochem. 2017;81(7):1417-1424.

15. Schulz KF, Altman DG, Moher D; CONSORT Group. CONSORT 2010 statement: updated guidelines for reporting parallel group randomized trials. Ann Intern Med. 2010;152(11):726-732.

16. Miyachi M, Tripette J, Kawakami R, Murakami H. “+10 min of physical activity per day": Japan is looking for efficient but feasible recommendations for its population. J Nutr Sci Vitaminol (Tokyo). 2015;61(Suppl):S7-S9.

17. Murakami H, Tripette J, Kawakami R, Miyachi M. "Add 10 min for your health": the new Japanese recommendation for physical activity based on dose-response analysis. J Am Coll Cardiol. 2015;65(11): $1153-1154$. 
18. Kurotani K, Akter S, Kashino I, et al; Japan Public Health Center based Prospective Study Group. Quality of diet and mortality among Japanese men and women: Japan Public Health Center based prospective study. BMJ. 2016;352:11209.

19. Yoshizumi T, Nakamura T, Yamane M, et al. Abdominal fat: standardized technique for measurement at CT. Radiology 1999;211(1):283-286.

20. Shafer KJ, Siders WA, Johnson LK, Lukaski HC. Validity of segmental multiple-frequency bioelectrical impedance analysis to estimate body composition of adults across a range of body mass indexes. Nutrition 2009;25(1):25-32.

21. Friedewald WT, Levy RI, Fredrickson DS. Estimation of the concentration of low-density lipoprotein cholesterol in plasma, without use of the preparative ultracentrifuge. Clin Chem 1972;18(6):499-502.

22. Oshima Y, Kawaguchi K, Tanaka S, et al. Classifying household and locomotive activities using a triaxial accelerometer. Gait Posture. 2010;31(3):370-374.

23. Ohkawara K, Oshima Y, Hikihara Y, Ishikawa-Takata K, Tabata I, Tanaka $\mathrm{S}$. Real-time estimation of daily physical activity intensity by a triaxial accelerometer and a gravity-removal classification algorithm. Br J Nutr. 2011;105(11):1681-1691.

24. Troiano RP, Berrigan D, Dodd KW, Mâsse LC, Tilert T, McDowell M. Physical activity in the United States measured by accelerometer. Med Sci Sports Exerc. 2008;40(1):181-188.
25. Gannon MC, Nuttall FQ. Amino acid ingestion and glucose metabolism-a review. IUBMB Life. 2010;62(9):660-668.

26. Blecher M, Merlino NS, Ro'Ane JT, Flynn PD. Independence of the effects of epinephrine, glucagon, and adrenocorticotropin on glucose utilization from those on lipolysis in isolated rat adipose cells. J Biol Chem. 1969;244(13):3423-3429.

27. Holm C. Molecular mechanisms regulating hormone-sensitive lipase and lipolysis. Biochem Soc Trans. 2003;31(Pt 6):1120-1124.

28. Carmen GY, Victor SM. Signalling mechanisms regulating lipolysis. Cell Signal. 2006;18(4):401-408.

29. Rayalam S, Della-Fera MA, Baile CA. Phytochemicals and regulation of the adipocyte life cycle. J Nutr Biochem. 2008;19(11):717-726.

30. Haemmerle G, Lass A, Zimmermann R, et al. Defective lipolysis and altered energy metabolism in mice lacking adipose triglyceride lipase. Science. 2006;312(5774):734-737.

31. Zechner R, Strauss JG, Haemmerle G, Lass A, Zimmermann R. Lipolysis: pathway under construction. Curr Opin Lipidol. 2005;16(3):333-340.

32. Robuffe-Scrive M, Anderson B, OIbe L, Bjorntorp. Metabolism of adipose tissue in intraabdominal depots in severely obese men and women. Metabolism. 1990;39(10):1021-1025.

33. Richeisen B, Pedersen SB, Moller-Pedersen T, Bak JF. Regional differences in triglyceride breakdown in human adipose tissue: effects of catecholamines, insulin, and prostaglandin E2. Metabolism. 1991;40(9):990-996. 


\section{Supplementary materials}

Table SI Per-protocol-based analyses for primary, secondary, and compliance outcomes $(n=28)$

\begin{tabular}{|c|c|c|c|c|c|}
\hline & $\begin{array}{l}\text { High-dose group } \\
(3,000 \mathrm{mg} / \mathrm{d}, \mathrm{n}=7)\end{array}$ & $\begin{array}{l}\text { Medium-dose } \\
\text { group }(1,500 \\
\mathrm{mg} / \mathrm{d}, \mathrm{n}=8)\end{array}$ & $\begin{array}{l}\text { Low-dose group } \\
(750 \mathrm{mg} / \mathrm{d}, \mathrm{n}=6)\end{array}$ & $\begin{array}{l}\text { Placebo group } \\
(0 \mathrm{mg} / \mathrm{d}, \mathrm{n}=7)\end{array}$ & $\begin{array}{l}p \text {-value } \\
\text { for } \\
\text { ANOVA }\end{array}$ \\
\hline \multicolumn{6}{|l|}{ Primary outcomes } \\
\hline \multicolumn{6}{|l|}{ Abdominal fat area, $\mathrm{cm}^{2}$} \\
\hline Total & $-\mid 7.4(-5|.6| 6.7)$, & $-21.4(-73.4,30.7)$ & $-27.9(-62.6,6.8)$ & $-16.1(-37.8,5.6)$ & 0.96 \\
\hline Subcutaneous & $-11.2(-30.2,7.8)$ & $-8.1(-45.0,28.7)$ & $-11.5(-34.1,11.1)$ & $-9.5(-26.3,7.2)$ & 1.00 \\
\hline Visceral & $-6.2(-27.2,14.8)$ & $-13.2(-29.2,2.7)$ & $-16.4(-43.0,10.3)$ & $-6.6(-19.7,6.6)$ & 0.75 \\
\hline \multicolumn{6}{|l|}{ Secondary outcomes } \\
\hline Weight, kg & $-1.32(-2.91,0.27)$ & $-1.40(-5.91,3.11)$ & $-1.33(-3.60,0.95)$ & $-0.25(-1.93,1.43)$ & 0.90 \\
\hline Waist circumference, $\mathrm{cm}$ & $-2.02(-3.92,-0.12)$ & $-0.70(-5.17,3.77)$ & $-1.97(-3.88,-0.06)$ & $0.09(-2.14,2.32)$ & 0.61 \\
\hline Fat mass, kg & $-0.44(-2.20,1.31)$ & $-1.33(-3.64,0.99)$ & $-2.13(-4.05,-0.22)$ & $-0.64(-2.29,1.00)$ & 0.50 \\
\hline Fat-free mass, kg & $-0.71(-2.03,0.60)$ & $0.00(-2.28,2.28)$ & $0.63(-0.70,1.97)$ & $0.39(-0.24,1.01)$ & 0.54 \\
\hline \multicolumn{6}{|l|}{ Fat mass, $\%$} \\
\hline Total & $-0.06(-1.99,1.87)$ & $-1.28(-3.04,0.49)$ & $-2.43(-4.85,-0.02)$ & $-0.66(-2.12,0.80)$ & 0.21 \\
\hline Right arm & $0.07(-2.92,3.07)$ & $-1.87(-3.86,0.11)$ & $-3.62(-6.18,-1.06)$ & $-1.03(-2.55,0.49)$ & 0.08 \\
\hline Left arm & $0.50(-2.74,3.74)$ & $-1.53(-3.24,0.19)$ & $-3.65(-6.70,-0.60)$ & $-1.09(-2.79,0.62)$ & 0.07 \\
\hline Trunk & $-0.17(-2.18,1.84)$ & $-1.34(-3.11,0.43)$ & $-2.48(-4.98,0.01)$ & $-0.61(-1.90,0.67)$ & 0.22 \\
\hline Right leg & $-0.01(-1.69,1.66)$ & $-0.92(-2.40,0.55)$ & $-2.18(-4.17,-0.20)$ & $-0.70(-2.01,0.61)$ & 0.18 \\
\hline Left leg & $-0.03(-1.76,1.70)$ & $-0.99(-2.39,0.41)$ & $-2.12(-4.04,-0.19)$ & $-0.80(-2.13,0.53)$ & 0.21 \\
\hline \multicolumn{6}{|l|}{ Blood pressure, $\mathrm{mmHg}$} \\
\hline Systolic & $-6.43(-11.12,-1.74)$ & $3.50(-4.77, \mathrm{I} I .77)$ & $-3.58(-11.40,4.24)$ & $-2.50(-11.64,6.64)$ & 0.16 \\
\hline Diastolic & $-9.14(-15.26,-3.02)$ & $-0.69(-4.49,3.11)$ & $-3.42(-7.68,0.85)$ & $-3.14(-8.93,2.64)$ & 0.05 \\
\hline \multicolumn{6}{|l|}{ Blood biochemical parameters } \\
\hline Triglycerides, mg/dL & $-19.3(-79.2,40.7)$ & $-25.5(-70.2,19.2)$ & $-32.7(-98.1,32.8)$ & $-2.9(-45.9,40.2)$ & 0.80 \\
\hline Total cholesterol, mg/dL & $-19.6(-43.8,4.6)$ & $-13.2(-29.1,2.6)$ & $-18.5(-35.7,-1.3)$ & $-11.1(-24.7,2.5)$ & 0.83 \\
\hline HDL cholesterol, mg/dL & $-6.57(-18.11,4.97)$ & $-4.12(-10.21,1.96)$ & $1.00(-8.15,10.15)$ & $-1.29(-5.48,2.91)$ & 0.43 \\
\hline LDL cholesterol, mg/dL & $-14.7(-35.7,6.3)$ & $-9.2(-19.9,1.4)$ & $-17.8(-35.7,-0.0)$ & $-10.6(-19.6,-1.5)$ & 0.75 \\
\hline Fasting blood glucose, $\mathrm{mg} / \mathrm{dL}$ & $-0.14(-7.96,7.68)$ & $0.88(-3.06,4.81)$ & $3.17(-17.13,23.47)$ & $1.14(-4.21,6.49)$ & 0.95 \\
\hline Glycated hemoglobin Alc, \% & $-0.03(-0.17,0.11)$ & $-0.01(-0.08,0.06)$ & $0.15(-0.02,0.32)$ & $0.11(-0.01,0.24)$ & 0.05 \\
\hline Fasting insulin, IU & $0.77(-2.15,3.69)$ & $-5.71(-16.96,5.54)$ & $-2.30(-5.36,0.76)$ & $0.56(-3.42,4.53)$ & 0.36 \\
\hline \multicolumn{6}{|l|}{ Compliance measures } \\
\hline \multicolumn{6}{|l|}{ Dietary intake } \\
\hline Total energy, kcal/d & $4.1(-56 \mid .0,569.2)$ & $-133.4(-588.1,321.3)$ & $-123.5(-448.3,201.3)$ & $-211.4(-474.7,51.8)$ & 0.86 \\
\hline Protein, g/d & $3.3(-13.2,19.7)$ & $-4.4(-16.6,7.8)$ & $-10.9(-31.4,9.5)$ & $-9.9(-16.9,-3.0)$ & 0.32 \\
\hline Fat, g/d & $-8.61(-28.27,11.04)$ & $-5.12(-23.26,13.01)$ & $5.57(-12.97,24.10)$ & $-8.06(-23.12,7.00)$ & 0.55 \\
\hline Carbohydrate, g/d & $21.8(-81.4,124.9)$ & $-16.1(-86.5,54.3)$ & $-38.3(-90.9,14.3)$ & $-20.9(-57.4,15.6)$ & 0.56 \\
\hline \multicolumn{6}{|l|}{ Physical activity } \\
\hline Daily step counts, steps/d & $2,594(-1,833,7,021)$ & $20(-2,192,2,232)$ & $3,65 I(-26 I, 7,562)$ & $365(-216,945)$ & 0.15 \\
\hline MVPA, $\mathrm{min} / \mathrm{d}$ & $17.2(-22.9,57.2)$ & $-7.5(-25.9,10.9)$ & $31.9(-1.7,65.5)$ & $3.3(-9.6,16.1)$ & 0.10 \\
\hline Locomotive MVPA, min/d & $19.1(-19.3,57.5)$ & $-1.8(-16.3,12.8)$ & $26.8(-2.6,56.2)$ & $6.4(-5.4,18.2)$ & 0.22 \\
\hline Non-locomotive MVPA, $\mathrm{min} / \mathrm{d}$ & $-1.95(-12.95,9.05)$ & $-5.7 \mid(-15.09,3.66)$ & $5.08(-3.22,13.38)$ & $-3.13(-8.45,2.19)$ & 0.24 \\
\hline
\end{tabular}

Notes: Data shown as mean ( $95 \%$ confidence intervals).

Abbreviations: ANOVA, analysis of variance; HDL, high-density lipoprotein; LDL, low-density lipoprotein; MVPA, moderate-to-vigorous physical activity. 
Table S2 Adverse events identified by participant's diary logs $(n=35)$

\begin{tabular}{|c|c|c|c|c|c|}
\hline & $\begin{array}{l}\text { High-dose group } \\
(3,000 \mathrm{mg} / \mathrm{d}, \mathrm{n}=9)\end{array}$ & $\begin{array}{l}\text { Medium-dose group } \\
(1,500 \mathrm{mg} / \mathrm{d}, \mathrm{n}=9)\end{array}$ & $\begin{array}{l}\text { Low-dose group } \\
(750 \mathrm{mg} / \mathrm{d}, \mathrm{n}=8)\end{array}$ & $\begin{array}{l}\text { Placebo group } \\
(0 \mathrm{mg} / \mathrm{d}, \mathrm{n}=9)\end{array}$ & $\begin{array}{l}\text { p-value for } \\
\text { chi-squared test }\end{array}$ \\
\hline Asthma & 0 & 0 & 0 & $I(I I)$ & 0.40 \\
\hline Tongue numbness & 0 & 0 & I (I3) & 0 & 0.32 \\
\hline Diarrhea & 0 & I (II) & I (I3) & $2(22)$ & 0.53 \\
\hline Constipation & 0 & 0 & 0 & I (II) & 0.40 \\
\hline Gastroenteritis & 0 & I (II) & 0 & 0 & 0.40 \\
\hline Fever & $2(22)$ & I (II) & $2(25)$ & 0 & 0.43 \\
\hline Influenza & 0 & 0 & $I(13)$ & 0 & 0.32 \\
\hline Headache & $\mathrm{I}(\mathrm{II})$ & 0 & 0 & $I(I I)$ & 0.57 \\
\hline Toothache & 0 & 0 & 0 & I (II) & 0.40 \\
\hline Excessive sweating & I (II) & 0 & 0 & 0 & 0.40 \\
\hline Frequent urination & 0 & 0 & I (I3) & 0 & 0.32 \\
\hline Fatigue & $\mathrm{I}(\mathrm{II})$ & 0 & $I(13)$ & 0 & 0.52 \\
\hline Foot pain & $I(I I)$ & $I(I I)$ & $I(13)$ & 0 & 0.77 \\
\hline Knee pain & $2(22)$ & 0 & 0 & 0 & 0.11 \\
\hline Calf pain & 0 & 0 & 0 & I (II) & 0.40 \\
\hline Leg lameness & I (II) & 0 & 0 & 0 & 0.40 \\
\hline Leg cramp & I (II) & 0 & 0 & 0 & 0.40 \\
\hline Shin pain & I (II) & 0 & 0 & 0 & 0.40 \\
\hline Muscle pain & I (II) & 0 & 0 & 0 & 0.40 \\
\hline Back pain & 0 & I (II) & 0 & 0 & 0.40 \\
\hline Scapular pain & I (II) & 0 & 0 & 0 & 0.40 \\
\hline Wrist pain & 0 & 0 & I (I3) & 0 & 0.32 \\
\hline
\end{tabular}

Notes: Data shown as No. (\%).

Table S3 Adverse events identified during the study period by blood pressure recordings and fasting blood test $(n=35)$

\begin{tabular}{|c|c|c|c|c|c|c|}
\hline & Reference ranges & $\begin{array}{l}\text { High-dose } \\
\text { group }(3,000 \\
\mathrm{mg} / \mathrm{d}, \mathrm{n}=9)\end{array}$ & $\begin{array}{l}\text { Medium-dose } \\
\text { group }(1,500 \\
\mathrm{mg} / \mathrm{d}, \mathrm{n}=9)\end{array}$ & $\begin{array}{l}\text { Low-dose } \\
\text { group }(750 \\
\mathrm{mg} / \mathrm{d}, \mathrm{n}=8)\end{array}$ & $\begin{array}{l}\text { Placebo } \\
\text { group } \\
(0 \mathrm{mg} / \mathrm{d}, \mathrm{n}=9)\end{array}$ & $\begin{array}{l}p \text {-value for } \\
\text { chi-squared } \\
\text { test }\end{array}$ \\
\hline Elevated diastolic BP & $<90 \mathrm{mmHg}$ & 0 & 0 & $I(13)$ & 0 & 0.32 \\
\hline Decreased total protein & $6.5-8.2 \mathrm{~g} / \mathrm{dL}$ & 0 & 0 & $2(25)$ & 0 & 0.07 \\
\hline Decreased AST & II-35 U/L & I (II) & 0 & 0 & 0 & 0.40 \\
\hline Elevated GGT & $\begin{array}{l}\leq 70 \cup / L \text { (male) } \\
\leq 33 \mathrm{U} / \mathrm{L}(\text { female })\end{array}$ & 0 & $\mathrm{I}(\mathrm{II})$ & 0 & 0 & 0.40 \\
\hline Elevated CPK & $\begin{array}{l}62-287 \mathrm{U} / \mathrm{L} \text { (male) } \\
45-163 \mathrm{U} / \mathrm{L} \text { (female) }\end{array}$ & 0 & 0 & 0 & $\mathrm{I}(\mathrm{II})$ & 0.40 \\
\hline Decreased CPK & $\begin{array}{l}62-287 \mathrm{U} / \mathrm{L} \text { (male) } \\
45-163 \mathrm{U} / \mathrm{L} \text { (female) }\end{array}$ & 0 & 0 & $I(13)$ & 0 & 0.32 \\
\hline Decreased total cholesterol & $130-219 \mathrm{mg} / \mathrm{dL}$ & $\mathrm{I}(\mathrm{II})$ & 0 & 0 & 0 & 0.40 \\
\hline Decreased HDL cholesterol & $\begin{array}{l}40-79 \mathrm{mg} / \mathrm{dL} \text { (male) } \\
40-90 \mathrm{mg} / \mathrm{dL} \text { (female) }\end{array}$ & $\mathrm{I}(\mathrm{II})$ & 0 & 0 & 0 & 0.40 \\
\hline Elevated LDL cholesterol & $70-139 \mathrm{mg} / \mathrm{dL}$ & I (II) & $\mathrm{I}(\mathrm{II})$ & 0 & 0 & 0.57 \\
\hline Elevated triglycerides & $30-149$ mg/dL & $\mathrm{I}(\mathrm{II})$ & 0 & 0 & $\mathrm{I}(\mathrm{II})$ & 0.57 \\
\hline Decreased urea nitrogen & $8.0-23.0 \mathrm{mg} / \mathrm{dL}$ & 0 & $\mathrm{I}(\mathrm{II})$ & $I(13)$ & 0 & 0.52 \\
\hline Elevated serum potassium & $2.5-4.5 \mathrm{mg} / \mathrm{dL}$ & $\mathrm{I}(\mathrm{II})$ & 0 & 0 & 0 & 0.40 \\
\hline Elevated serum iron & $\begin{array}{l}60-190 \mu \mathrm{g} / \mathrm{dL} \text { (male) } \\
45-170 \mu \mathrm{g} / \mathrm{dL} \text { (female) }\end{array}$ & 0 & 0 & 0 & $\mathrm{I}(\mathrm{II})$ & 0.40 \\
\hline Decreased serum iron & $\begin{array}{l}60-190 \mu \mathrm{g} / \mathrm{dL} \text { (male) } \\
45-170 \mu \mathrm{g} / \mathrm{dL} \text { (female) }\end{array}$ & 0 & $\mathrm{I}(\mathrm{II})$ & 0 & $\mathrm{I}(\mathrm{II})$ & 0.57 \\
\hline Elevated A/G & $1.10-2.00$ & 0 & 0 & $I(13)$ & 0 & 0.32 \\
\hline Elevated WBC & $\begin{array}{l}3,900-9,700 \text { count } / \mu \mathrm{L} \text { (male) } \\
3,500-9,100 \text { count } / \mu \mathrm{L} \text { (female) }\end{array}$ & 0 & 0 & $I(13)$ & 0 & 0.32 \\
\hline Elevated hematocrit & $\begin{array}{l}40.4 \%-51.9 \% \text { (male) } \\
34.3 \%-45.2 \% \text { (female) }\end{array}$ & $\mathrm{I}(\mathrm{II})$ & 0 & 0 & 0 & 0.40 \\
\hline Elevated HOMA-R & $\leq 1.6$ & $2(22)$ & $2(22)$ & $I(13)$ & $2(22)$ & 0.95 \\
\hline
\end{tabular}

Notes: Data shown as No. (\%)

Abbreviations: A/G, albumin/globulin; AST, aspartate aminotransferase; BP, blood pressure; CPK, creatine phosphokinase; GGT, gamma-glutamyltransferase; HDL, highdensity lipoprotein; HOMA-R, homeostasis model assessment insulin resistance; LDL, low-density lipoprotein; WBC, white blood cell. 
Diabetes, Metabolic Syndrome and Obesity: Targets and Therapy

Diabetes, Metabolic Syndrome and Obesity: Targets and Therapy is an international, peer-reviewed open-access journal committed to the rapid publication of the latest laboratory and clinical findings in the fields of diabetes, metabolic syndrome and obesity research. Original research, review, case reports, hypothesis formation, expert opinion and commentaries are all considered for publication. The manuscript management system is completely online and includes a very quick and fair peer-review system, which is all easy to use. Visit http://www.dovepress.com/testimonials.php to read real quotes from published authors.

Submit your manuscript here: https://www.dovepress.com/diabetes-metabolic-syndrome-and-obesity-targets-and-therapy-journal 